\title{
Mental health literacy and psychological distress as predictors of psychological well-being in Sriwijaya University students
}

\author{
Sayang Ajeng Mardhiyah
}

Psychology Department, Medical Faculty University Sriwijaya

\begin{abstract}
Introduction. This research focused on answering questions: how mental health literacy and psychological distress act as predictors of psychological well-being in Sriwijaya University students.

Methodology. This research used quantitative method, by conducting instrument preparation, data collection, and analysis of data results to see the role of the independent variables on the dependent variable. Psychological well-being was measured using an instrument in a form of psychological scale referred to Psychological Scale by Ryff \& Keyes (1995). Meanwhile, psychological distress was measured using WHO Self-Reporting Questionnaire 20 (SRQ-20) Indonesian version, and Mental Health Literacy measurement was adapted from O'Connor and Casey (2015). The participants of this research were consisted of 418 college students.
\end{abstract}

Results. The analysis results show that there is a role of mental health literacy and psychological distress together on psychological well-being, thus the hypothesis is accepted. Major hypothesis test was done using multiple linear regression which shows a correlation value (R) of 0.586 and a significance of $0.001(p<0.05)$. For the results of minor hypothesis test, it is known that the beta value is 0.143 and the $P$ value is 0.022 ( $p>0.05$ ), this indicates that there is a role for mental health literacy on psychological well-being, thus the hypothesis is accepted. In addition, it is known that psychological well-being and psychological distress show a beta value of -1.945 and a $P$ value of 0.001 ( $p>0.05$ ), this indicates that there is a role for psychological distress on psychological well-being thus the hypothesis is accepted.

Conclusions. The percentage of mental health literacy and psychological pressure influences on psychological well-being (R adjusted) is 0.343 , this also shows that the contribution of mental health literacy and psychological distress together on psychological well-being is $34.3 \%$, while the rest is the contribution of other variables not examined in this study.

\section{Keywords}

mental health literacy, psychological distress, psychological well being

Address for correspondence:

Sayang Ajeng Mardhiyah, Psychology Departement, Medical Faculty University

Sriwijaya. email : ajeng_mardhiyah.psi@fk.unsri.ac.id

This work is licensed under a Creative Commons Attribution-

NonCommercial 4.0 International License (CC BY-NC 4.0).

\section{(c) (i) (8)}

(C) Copyright: Sayang Ajeng Mardhiyah, 2021

Submitted for publication: 25 August 2021

Revised: 03 October 2021 Accepted for publication: 24 October 2021

Licensee NDSAN (MFC- Coordinator of the NDSAN), Italy

doi: https://doi.org/10.32437/mhgcj.v4i1.1 14 


\section{Introduction}

The World Health Organization (WHO), describes mental health as a state in which a person realizes their abilities, able to deal with normal stressors, able to work productively and pleasantly, and able to contribute to the community (WHO, 2005). It can be said that, if there are obstacles in carrying out these functions, the individual may have problems with their mental health.

The increase in mental disorders obtained from Basic Health Research Indonesian Ministry of Health (riskesdas) in 2018, shows a significant increase compared to Riskesdas in 2013, which increase from 1.3\% to 7\% (Indonesian Ministry of Health, 2018). This increase was revealed from the increase in the prevalence of households with people with mental disorders (ODGJ) in Indonesia.

Johanna Jarcho, Ph.D., a postdoctoral at National Institute of Mental Health, said that most mental health disorders appear in their teens or early 20s. The symptoms usually begin in childhood or adolescence and will continue into adulthood. Most people don't realize that they had an anxiety disorder when they were teenagers, and realize it as an adult. Teenagers have the potential to experience mental health problems such as school problems, college, lack of sleep, and romance, so it is not uncommon for them to choose drugs and alcohol to forget about those problems (Women's Brain Health Initiative, 2015).

It is estimated that mental disorders in children and adolescents will become one of the five problems that cause disability, morbidity, or even mortality in the next 20 years (WHO, 2013). Mental health problems in children and adolescents can affect their functioning in important domains in their lives now and the future, such as functioning at school, at home, with friends, and in the community (Jaycox et al., 2009).

Likewise, when teenagers enter university, students' mental health issues become a very common discussion (Blanco C. et al., 2008). In general, it is known that every individual has the potential to experience mental health disorders, from children to adults. In children, it is too early for them to understand mental health, so research has focused more on adolescents. This is because in adolescence, the cognitive development has finally able to receive information abstractly and rationally, it also can process this information in everyday life. Furthermore, for early prevention before mental disorders occur in adulthood, adolescents also need to understand about mental health itself. In this context, many students experience the onset of mental health problems or even worsen initial conditions that students have experienced before entering university (Burns \& Rapee, 2006; Pedrelli et al., 2014;).

Screening results on 147 Unsri students conducted by researcher at the time of community service in 2019 , found $56.5 \%$ of the students experienced mild symptoms of psychological distress, $40.1 \%$ experienced symptoms of high psychological distress (needs to be wary of), and only $3.4 \%$ did not show symptoms of psychological distress, such as depression, anxiety and somatic complaints (Mardhiyah, 2019).

Low mental health literacy and psychological distress are considered predictors of low psychological well-being (Farrer, Leach, Griffiths, Christensen, \& Jorm, 2008; Burns \& Rapee, 2006) and even dropping out of college (NAMl, 2012). Mental health literacy is knowledge and beliefs about mental disorders related to recognition, management, or prevention (Jorm, 2000). This means that individuals with mental health literacy have knowledge about mental disorders, their causes, symptoms, and treatments. Mental health literacy (Jorm, 2000) consists of several components including: 1) the ability to recognize specific disorders or differences in types of psychological distress, 2) knowledge and beliefs about risk factors and causes, 3) knowledge and understanding of self-help interventions, 4) knowledge and beliefs about mental health disorders.

Based on the background of the study, the researcher was interested to analyze mental health literacy and psychological distress as predictors for psychological well-being of collage students in Sriwijaya University.

\section{Purpose}

This research focused on answering questions as below:

1. Is there a role of mental health literacy and psychological distress on the psychological wellbeing of collage students in Sriwijaya University?

2. Is there a role of mental health literacy on the psychological well-being of collage students in Sriwijaya University?

3. Is there a role of psychological stress on the psychological well-being of collage students in Sriwijaya University?

\section{Design/Methodology/Approach}

This research used quantitative method, by conducting instrument preparation, data collection, and analysis of data results to see the role of the independent variables on the dependent variable. 


\section{Research Population and Sample}

The population in this study are active students in Sriwijaya University. The sampling technique used is the incidental sampling which is a sampling technique based on respondents who are met and meet the criteria. In this study, samples were taken based on individual's willingness to fill out the research scale.

The selection of the number of samples in this study refers to Roscoe's theory (Sugiyono, 2016). Roscoe suggested a suitable sample size for research ranging from 30 to 500 (Sugiyono, 2016). In this study, the participants were 418 college students.

\section{Data collecting methods}

Psychological well-being was measured using an instrument in a form of psychological scale referred to the psychological concept proposed by Ryff and Keyes (1995), which describes individual functioning to be independent, realize their potential, able to master their environment, able to accept themselves, have a purpose in life, and able to have a positive relationship with others. The Indonesian version of the Ryff and Keyes (1995) psychological well-being scale developed by Rachmayani and Rachmadani (2014) was modified and a try out was carried out to 50 respondents before being distributed. This was done to measure the validity and reliability of the measuring instrument. The reliability before tryout with 86 items was 0.871 and after try-out with 43 items was 0.923 (data attached).

Furthermore, the concept of psychological distress is used as an indicator of mental health which is defined as a multifactorial and unpleasant emotional experience of psychological (cognitive, behavioral, emotional), social, and spiritual traits that may interfere with the ability to effectively cope with illness, physical symptoms, and treatments (Reis et al., 2014). In this case, the researcher measured psychological distress using the Indonesian version of the WHO Self-Reporting Questionnaire 20 (SRQ-20), with a scoring scale of Yes (1) and No (0). This instrument has been used in Basic Health Research (Riskesda) of Indonesian population, which aims to determine mental health status. One of the reasons is because this questionnaire has good validity in terms of sensitivity of $88 \%$, and specificity of $81 \%$ (Hartono, 1995).

Meanwhile, mental health literacy concept is defined as knowledge and beliefs about mental disorders that aid in the recognition, management, or prevention. Mental health literacy includes the ability to recognize specific disorders; knowing how to seek mental health information; knowledge of risk factors and causes; knowledge of self-treatments; knowledge of professional help available; and attitudes that promote recognition and appropriate helpseeking (O'Connor \& Casey, 2014). To measure mental health literacy, a standardized scale was adapted from O'Connor and Casey (2015) which was translated into Bahasa, with permission and guidance from O'Connor.

\section{Results}

\section{Description of Participants}

The number of participants in this study were 418 college students.

Based on the gender data, it is known that there are 129 male participants (30.9\%) and 289 female participants $(69.1 \%)$. Meanwhile for the age data, there are 150 adolescent participants $(35.9 \%)$ and 268 young adult participants $(64,1 \%)$

\begin{tabular}{|c|c|c|c|}
\hline \multicolumn{2}{|c|}{$\begin{array}{c}\text { Frequen } \\
\text { cy }\end{array}$} \\
\hline \multirow{2}{*}{ Gender } & Male & 129 & $30,9 \%$ \\
\cline { 2 - 4 } & Female & 289 & $69,1 \%$ \\
\hline \multirow{2}{*}{ Age } & Adolescence & 150 & $35,9 \%$ \\
\cline { 2 - 4 } & $\begin{array}{c}\text { Early } \\
\text { adulthood }\end{array}$ & 268 & $64,1 \%$ \\
\hline Participate in Non- & Yes & 264 & $63,4 \%$ \\
Academic Activities & No & 154 & $36,6 \%$ \\
\hline Semester & 2 & 153 & $36,6 \%$ \\
\cline { 2 - 4 } & 4 & 85 & $20,3 \%$ \\
\cline { 2 - 4 } & 6 & 108 & $25,8 \%$ \\
\cline { 2 - 4 } & 8 & 52 & $12,5 \%$ \\
\cline { 2 - 4 } & 10 & 2 & $3,8 \%$ \\
\cline { 2 - 4 } & 12 & \multicolumn{2}{c}{} \\
\hline
\end{tabular}




\section{Description of Research Data}

This study was analyzed descriptively on each variable. The following is a description of each variable

\begin{tabular}{|c|c|c|c|c|c|c|c|c|}
\hline \multirow{2}{*}{ Variable } & \multicolumn{4}{|c|}{ Hypothetical Data } & \multicolumn{4}{c|}{ Empirical Data } \\
\cline { 2 - 9 } & Max & Min & Mean & SD & Max & Min & Mean & SD \\
\hline $\begin{array}{c}\text { Mental } \\
\text { Health } \\
\text { Literacy }\end{array}$ & 175 & 35 & 105 & 23,3 & 137 & 77 & 109,775 & 9,478 \\
\hline $\begin{array}{c}\text { Psychological } \\
\text { Distress }\end{array}$ & 20 & 6 & 13 & 2,3 & 20 & 0 & 7,175 & 4,401 \\
\hline $\begin{array}{c}\text { Psychological } \\
\text { Well-Being }\end{array}$ & 172 & 43 & 107,5 & 21,5 & 163 & 82 & 123,077 & 14,867 \\
\hline
\end{tabular}

Description: Min: Minimum Total Score; Max: Maximum Total Score; Mean: Mean Score; SD:Standard Deviation.

Besides that, researcher also classified the participants into certain categories for variable of mental health literacy and psychological wellbeing. This categorization serves a purpose to place individuals into groups in which positions are tiered according to a continuum based on the measured attributes. Classification of participants was done through three kinds of categories, namely: low, average, and high.

Meanwhile, for psychological distress, the Indonesian version of WHO Self-Reporting Questionnaire 20 (SRQ-20) was used. Specifically, the interpretation of SRQ-2O total score is (Medhin, Hanlon, Dewey, Alem, Tesfaye, Lakew, et al, 2010):

Table of SRQ-20 Total Score Categorization

\begin{tabular}{|l|l|}
\hline SRQ-20 Total Score & Categorization \\
\hline 0 & $\begin{array}{c}\text { No symptoms of psychological distress, such as depression, anxiety and } \\
\text { somatic complaints }\end{array}$ \\
\hline $1-5$ & $\begin{array}{c}\text { There are mild symptoms of psychological distress } \\
\text { Experiencing symptoms of high psychological distress (needs to be } \\
\text { wary of) }\end{array}$ \\
\hline
\end{tabular}

Based on the formula above, the categorization for each variable is as follows: 
Table of Categorization of Participants': Mental Health Literacy, Psychological Distress and Psychological Well-Bein

\begin{tabular}{|c|c|c|c|c|}
\hline & & Categorization & $\begin{array}{l}\text { Frequen } \\
\text { cy }\end{array}$ & Percentage \\
\hline Mental & $X<81,7$ & Low & 2 & $0,5 \%$ \\
\hline Literacy & $\begin{array}{l}81,7 \leq X< \\
128,3\end{array}$ & Average & 402 & $96,2 \%$ \\
\hline & $x \geq 128,3$ & High & 14 & $3,3 \%$ \\
\hline $\begin{array}{l}\text { Psychological } \\
\text { Distress }\end{array}$ & $x<1$ & $\begin{array}{l}\text { No symptoms of } \\
\text { psychological distress }\end{array}$ & 21 & $5,0 \%$ \\
\hline & $1 \leq x<6$ & \begin{tabular}{l}
\multicolumn{1}{c}{ Showing mild } \\
symptoms of \\
psychological distress
\end{tabular} & 140 & $33,5 \%$ \\
\hline & $x \geq 6$ & $\begin{array}{l}\text { Showing symptoms of } \\
\text { high } \\
\text { distress }\end{array}$ & 257 & $61,5 \%$ \\
\hline Psychological Well- & $x<86$ & Low & 4 & $1 \%$ \\
\hline Being & $86 \leq X<129$ & Average & 263 & $62,9 \%$ \\
\hline & $x \geq 129$ & High & 151 & $36,1 \%$ \\
\hline
\end{tabular}

\section{Results}

\section{Data analysis results}

Assumption test

\section{1) Normality test}

Before testing the hypothesis, the researcher conducted a normality test first, because to test the hypothesis, the data are required to be normally distributed. Normality of a data can be

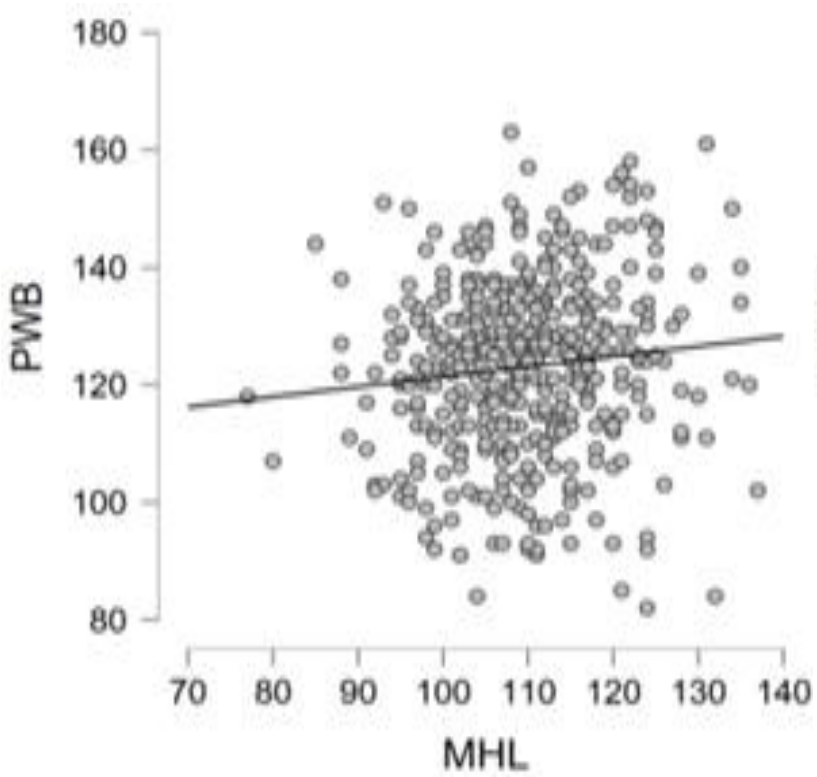

\section{2) Linearity test}

One of the other requirements before testing the hypothesis is that there is a linear relationship recognized or detected by looking at the distribution of data (dots) on the diagonal axis of the plot graph and its residuals. Data can be said to be normally distributed if the dots spread around the diagonal line and follow the direction of the diagonal line.

Based on the plot graph output, the dots follow and approach the diagonal line thus it can be concluded that the data are normally distributed.

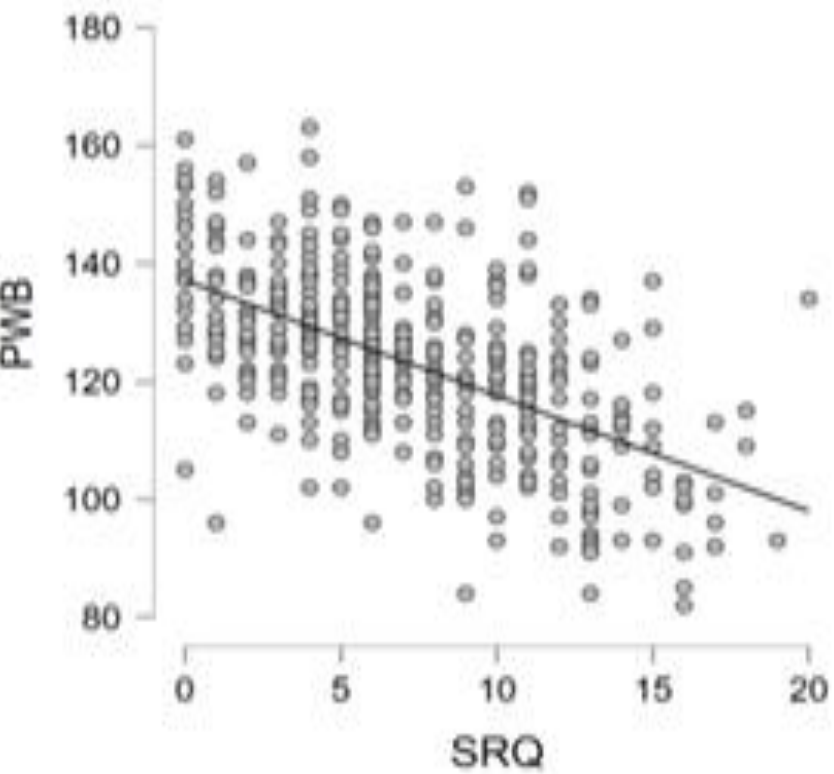

between variables. To find out whether there is a linear relationship or not between each variables, a linearity test was carried out. The results of the linearity test are as follows: 
Table of Linearity Test Results

\begin{tabular}{|c|c|c|c|}
\hline \multirow{2}{*}{ Variables } & \multicolumn{2}{|c|}{ Linearity } & \\
\cline { 2 - 3 } & Pearson's $r$ & p-value. & Description \\
\hline $\begin{array}{c}\text { Psychological Well- } \\
\text { Being -- Mental Health } \\
\text { Literacy }\end{array}$ & 0,110 & 0,025 & Linear \\
\hline $\begin{array}{c}\text { Psychological Well- } \\
\text { Being -- Psychological } \\
\text { Distress }\end{array}$ & $-0,578$ & $<0,001$ & Linear \\
\hline
\end{tabular}

Based on the linearity test, the significance value of psychological well-being and mental health literacy variables is 0.025; while psychological distress is $0.001(\mathrm{p}<0.05)$, thus it can be concluded that the variables have a linear relationship.

\section{3) Multicollinearity test}

Multicollinearity test is used to see whether the independent variables have a perfect or near perfect linear relationship, because a good regression model should not have a perfect correlation between the independent variables. Multicollinearity test was carried out by looking at the Variance Inflation Factor (VIF).

According to Ghozali (in Purnomo, 2016), if the VIF value is $<10$ then there is no symptom of multicollinearity among the independent variables, and if the VIF value is $>10$ then multicollinearity occur among the independent variables. The results of the multicollinearity test can be seen in the following table:

Table of Multicollinearity Test Results Summary

\begin{tabular}{|c|c|c|c|}
\hline \multirow{2}{*}{ Variables } & \multicolumn{2}{|c|}{ Collinearity Statistics } & Description \\
\hline & Tollerance & VIF & \\
\hline $\begin{array}{l}\text { Psychological Well- } \\
\text { Being -- Mental Health } \\
\text { Literacy }\end{array}$ & 0,999 & 1,001 & No multicollinearity \\
\hline $\begin{array}{l}\text { Psychological Well- } \\
\text { Being -- Psychological } \\
\text { Distress }\end{array}$ & 0,999 & 1,001 & No multicollinearity \\
\hline
\end{tabular}

From these results, it can bee seen that the variable of mental health literacy and psychological well-being has a VIF of 1.001, meaning that the VIF value is smalled than 10 $(1.001<10)$, thus it can be conclude that there is no symptom of multicollinearity among the independent variables.

\section{4) Heteroscedasticity test}

This test is carried out to see whether the variance of the variables is not the same for all observation, because heteroscedasticity should not occur in a good regression. In this study, to see whether there

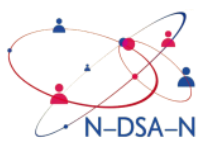


is heteroscedasticity, the researcher used scatterplots; namely by looking at the pattern of dots on the regression scatterplots. The method is to create a plot or scatter graph between Standardized Predicted Value (ZPRED) and Studentized Residual (SRESID). Whether or not there is a certain pattern on the scatterplot graph between SRESID and ZPRED can be seen from the $Y$ axis which has been predicted and the $X$ axis which is the residual (predicted $Y$ - true $Y$ ).

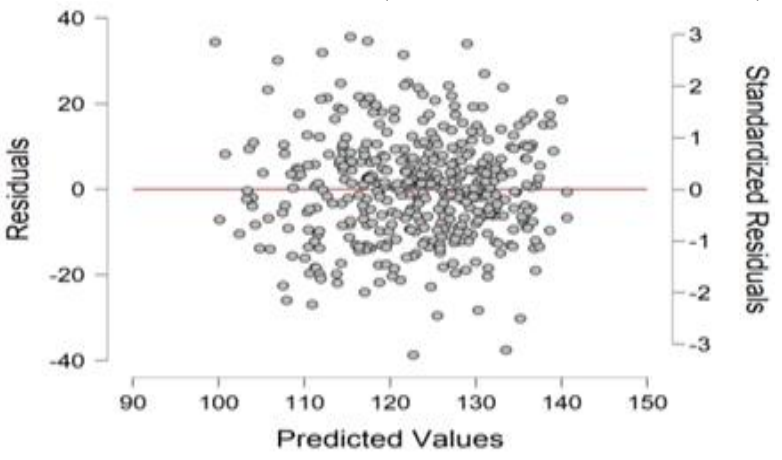

From the results of heteroscedasticity test, it can be seen that the dots spread above and below the number 0 on the $Y$ axis, which means that there is no symptom of heteroscedasticity.

\section{Hypothesis testing}

To test the hypothesis, the researcher used regression analysis. In this study, multiple regression analysis is used to determine the role of mental health literacy and psychological distress on psychological well-being. The result of the regression analysis is as follows:

Table of Major Hypothesis Testing Results

\begin{tabular}{|c|c|c|c|c|c|}
\hline Variables & $\mathrm{R}$ & R Square & $\mathrm{F}$ & Sig & Description \\
\hline $\begin{array}{l}\text { Mental Health } \\
\text { Literacy - } \\
\text { Psychological } \\
\text { Distress - } \\
\text { Psychological } \\
\text { Well-Being }\end{array}$ & 0,586 & 0,343 & 108,416 & $<0,001$ & Significant \\
\hline
\end{tabular}

Based on the table, it is known that the significance value of psychological well-being, mental health literacy, and psychological distress is 0.001 $(\mathrm{p}<0.05)$ with a correlation coefficient (R) of 0.586 . These results show that there is a role of mental health literacy and psychological distress together on psychological well-being, thus the hypothesis is accepted.

The percentage of mental health literacy and psychological distress influences on psychological well-being (R adjusted) is 0.343 , this also shows that the role of mental health literacy and psychological distress together on psychological well-being is $34.3 \%$, while the rest is the contribution of other variables not examined in this study. 
Table of Minor Hypothesis Testing Results

\begin{tabular}{|l|l|l|l|}
\hline Variables & Beta & P & Significance \\
\hline $\begin{array}{l}\text { Mental Health Literacy - } \\
\text { Psychological Well-Being }\end{array}$ & 0,143 & 0,022 & Significant \\
\hline $\begin{array}{l}\text { Psychological Distress - } \\
\text { Psychological Well-Being }\end{array}$ & $-1,945$ & $<0,001$ & Significant \\
\hline
\end{tabular}

Based on the table above, it can be seen that psychological well-being and mental health literacy show a beta value of 0.143 and a $P$ value of $0.022(p<0.05)$, this indicates that there is a role for mental health literacy on psychological wellbeing, thus the hypothesis is accepted.

It can also be seen that psychological wellbeing and psychological distress show a beta value of -1.945 and a $P$ value of $0.001 \quad(p<0.05)$, this indicates that there is a role for psychological distress on psychological well-being, thus the hypothesis is accepted.

To determine how big the role of mental health literacy and psychological distress on psychological well-being, the researcher conducted an analysis to find the effective contribution of the variables. By using the following formula:

$\mathrm{SE}(\mathrm{X}) \%=$ Beta $_{\mathrm{x}}$. Zero Order . $100 \%$

Thus it is known that the effective contribution of mental health literacy is $1.001 \%$ and psychological distress is $33.35 \%$ on mental health.

\section{Table of Effective Contribution Data of Mental Health Literacy and Psychological Distress on Psychological Well-Being}

\begin{tabular}{|c|c|c|}
\hline Variable & Beta & Zero Order \\
\hline $\begin{array}{c}\text { Mental Health } \\
\text { Literacy }\end{array}$ & 0,091 & 0,110 \\
\hline Psychological Distress & $-0,576$ & $-0,579$ \\
\hline
\end{tabular}

Table of Effective Contribution Summary

\begin{tabular}{|c|c|c|}
\hline Variables & Effective Contribution \\
\hline $\begin{array}{c}\text { Mental Health Literacy } \\
- \text { Psychological Well- } \\
\text { Being }\end{array}$ & $(0,091) \times(0,110) \times 100 \%$ & $1,001 \%$ \\
\hline $\begin{array}{c}\text { Psychological Distress - } \\
\text { Psychological Well- } \\
\text { Being }\end{array}$ & $(-0,576) \times(-0,579) \times 100 \%$ & $33,35 \%$ \\
\hline
\end{tabular}

\section{Discussion}

In this study, the major hypothesis testing was carried out using multiple linear regression which showed correlation value (R) of 0.586 and a significance of $0.001 \quad(p<0.05)$. These results show that there is a role of mental health literacy and psychological distress together on psychological well-being, thus the hypothesis is accepted.

Meanwhile, the percentage of mental health literacy and psychological distress influences on psychological well-being ( $\mathrm{R}$ adjusted) is 0.343 , this also shows that the role of mental health literacy and psychological distress together on psychological well-being is $34.3 \%$, while the rest is the contribution of other variables not examined in this study. According to Ryff (1995), several factors that may affect psychological well-being are age, gender, and culture. Then Ryff et al. (2002) also 
added several more factors including educational status and personality.

For the results of the minor hypothesis testing, it is known that the beta value is 0.143 and the $P$ value is $0.022(p>0.05)$, this indicates that there is a role for mental health literacy on psychological well-being, thus the hypothesis is accepted.

In addition, psychological well-being and psychological distress show a beta value of -1.945 and a P value of $0.001(\mathrm{p}<0.05)$, this indicates that there is a role for psychological distress on psychological well-being, thus the hypothesis is accepted. Specifically, the effective contribution of mental health literacy is $1.001 \%$ and psychological distress is $33.35 \%$ on mental health.

Several previous researches indicate that university should planning intervention and promotion of psychological well-being, to increase awareness and ability to conceptualize mental and emotional health for collage students (Vazquez, 2016). Learning and adopting knowledge related to health promotion and behavior during adolescence can improve healthy decision making and health literacy in collage, including mental health literacy, which in particular also has a component of knowledge around mental health itself (Bjørnsen et al., 2019). Therefore, mental health literacy interventions are suggested in promoting psychological well-being as the result itself rather than focusing solely on curative mental disorders (Vazquesz, 2016).

Adolescence is also a period when individuals are vulnerable to psychological distress, and so this period is an important time to promote psychological well-being and early intervention for mental health, as an effort to avoid the occurrence of mental health problems (Pengpid, \& Peltzer, 2020). One of the interventions that can be done is mental health literacy intervention as described above. Research on mental health literacy will lead to planning for mental health promotion in order to reduce the occurrence and severity of mental disorders, so the promotion of mental health literacy becoming important to promote psychological well-being and prevent mental health problems (Inchaithep, Punsawat, \& Nuntana, 2018).

Ashfield and Smith (Male Suicide Prevention Australia, 2018) through their discussion of suicide prevention, also explained that it is not only important to reach an approach on how to respond to psychological distress and mental health disorders, but also to be involved in preventive promotion (in this case suicide prevention), improvement on psychological wellbeing, and mental health literacy. Moreover, one of the components of mental health literacy mentioned by Jorm (2000) is the ability to recognize specific disorders or differences in various psychological distresses. Thus, both mental health literacy and psychological distress are considered having a role in improving psychological well-being.

The results and discussion above indicate that the hypothesis which states there is a role of mental health literacy and psychological distress on psychological well-being can be accepted. Given that there are still $65.7 \%$ of other factors unidentified in this study, for further research, other variables can be added as predictors of psychological well-being, including adjustment, emotion, personality type, stress management, social support, and others.

The results also show that $61.5 \%$ students have high psychological distress, $33.5 \%$ on average level, and another 5\% on low level of psychological distress. This is in line with what Jarcho (Womens Brain Health Initiative (2015) said that most adolescents in university experience psychological distress.

Psychological distress is a state of emotional distress that affects psychological well-being, this condition is characterized by symptoms of depression (e.g. loss of interest, sadness, hopelessness) and anxiety (e.g. restlessness, feeling tense) (Mirowsky \& Ross, 2003). The level of psychological distress can be caused by two influences, namely: intrapersonal, such as personality traits; and situational influences, such as life events (Matthews, 2000). Situational factors from the environment that encourage psychological distress include traumatic events, physical factors, social factors, and poor health (Matthews, 2000). Therefore, there should be preventative efforts that universities can come up with in this regard.

In this study, the researcher also conducted additional analysis by conducting difference tests on variables of psychological well-being, mental health literacy, and psychological distress based on gender, age, participation in non-academic activities and semester of lectures. From those tests, differences are found in age for all variables and both in gender and semester for the variables of mental health literacy and psychological distress. The difference in gender and mental health literacy variables is in line with several previous studies (Dias et al., 2018; Cotton et al., 2006), where women have higher mental health literacy scores than men. Gender differences found in psychological distress variable are also in line with several previous studies (Campbell, Bann, \& Patalay, 2021; Tian et al., 2021), where women have higher mental health problems than men, and the biggest difference is in life satisfaction and 
psychological distress (Campbell, Bann, \& Patalay, 2021).

\section{Limitations of the study}

In this study, the researcher limits the scope of the research so that the research objectives can be achieved properly:

1) This research was conducted on active Sriwijaya University students

2) Individual characterisrics data was obtained from personal data of students involved as participants in this research

\section{Conclusions (and Future Work)}

The percentage of mental health literacy and psychological pressure influences on psychological well-being (R adjusted) is 0.343 , this also shows that the contribution of mental health literacy and psychological distress together on psychological well-being is $34.3 \%$, while the rest is the contribution of other variables not examined in this study.

Future work, it is important that university planning an intervention and promotion of psychological well-being, to increase awareness and ability to conceptualize mental and emotional health for collage students. Learning and adopting knowledge related to health promotion and behavior during in collage; can improve healthy decision making and health literacy in adolescents, including mental health literacy, which in particular also has a component of knowledge around mental health itself. Research on mental health literacy will lead to planning for mental health promotion in order to reduce the occurrence and severity of mental disorders.

\section{Acknowledgments}

This research is expected to be able to contribute to the development of knowledge in the field of mental health regarding mental health literacy, psychological distress, and psychological well-being of collage students in Sriwijaya University.

\section{Conflict of interest}

Author declares that she has no conflict of interests

\section{References}

Agteren, J. V., Woodyatt, L., lasiello, M., Rayner, J., Kyrios, M (2019). Make it Measurable: Assessing Psychological Distress, Wellbeing and Resilience at Scale in Higher Education Student
Success (studentsuccessjournal.org). Volume $10 \quad$ (3) 2019. https://doi.org/10.5204/ssj.v10i3.1411

Ashfield, J. \& Smith, A. (2018). The situational approach to suicide prevention and mental health literacy: Advocating for a new multisector and multidisciplinary approach, Male Suicide Prevention Australia. https://malesuicidepreventionaustralia.com.au /wp-content/uploads/2018/02/SA-Advocating for-a-new-multi-sector-approach-190218.pdf.

Bjornsen, H.N., Espnes, G.A., Eilertsen, M-E.B., Ringdal, R., \& Moksnes, U.K. (2019). The relationship between positive mental health literacy and mental wel-being among adolescents: Implications for school health services. The Journal of School Nursing, 35(2), 107-116. Doi: 10.1177/1059840517732125.

Blanco C, et al. (2008). Mental health of college students and their non-college-attending peers: Results from the National Epidemiologic Study on Alcohol and Related Conditions. Arch Gen Psychiatry;65(12): 1429-37

Burns, J. R., \& Rapee, R. M. (2006). Adolescent mental health literacy: Young people's knowledge of depression and help seeking. Journal of adolescence, 29(2), 225-239.

Campbell, O.L.K, Bann, D., \& Patalay, P. (2021). The gender gap in adolescent mental health: A cross-national investigation of 566,829 adolescents across 73 countries. SSM Population Health, $13 . \quad$ Doi: https://doi.org/10.1016/j.ssmph.2021. 100742.

Cotton, S.M., Wright, A., Harris, M.G., Jorm, A.F., \& Mcgorry, P.D. (2006). Influence of gender on mental health literacy in young Australians. Australian \& New Zealand Journal of Psychiatry, 40(9), 790-796. Doi: https//doi.org/10.1080/j. 14401614.2006.01885.x.

Dias, P., Campos, L., Ameida, H., \& Palha, F. (2018). Mental health literacy in young adults: Adaptaion and psychometric properties of the mental health literacy questionnaire. Int. J. Environ. Res. Public Health, 15 (1318), 1-13. Doi: 10.3390/ijerph15071318.

Farrer, L., Leach, L., Griffiths, K. M., Christensen, H., \& Jorm, A. F. (2008). Age differences in mental health literacy. BMC Public Health, 8(1).

Inchaithep, S., Punsawat, M., \& Nuntana. (2018). Mental health literacy among people in Lampang Province, Thailand. The 6th Asian Academic Society International Conference (AASIC), 73-78.

Jorm, A.F., Korten, A.E., Jacomb, P.A., Christensen, H., Rodgers, B., \& Pollitt, P. (1997). "Mental health literacy": a survey of the public's ability to recognise mental disorders and their beliefs

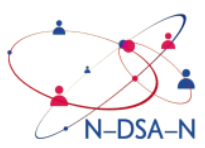


about effectiveness of treatment. Med J Austral, 166, 182-186.

Jorm, A. F. (2000). Mental health literacy: Public knowledge and beliefs about. British Journal of Psychiatry, 177, 396-401.

Jorm, A.F. (2012). Mental health literacy: Empowering the community to take action for better mental health. American Psychological Association, 67(3), 231-243. Doi: 10.1037/a0025957.

Jaycox, L. H., Langley, A. K., Stein, B., Wong, M., Sharma, P., Scott, M., \& Schonlau, M. (2009). Support for students exposed to trauma: A pilot study. School Mental Health, 1(2), 49-60. doi: 10.1007/s1 2310-009-9007-8

Mardhiyah, SA., Iswari, R.D. \& Juniarly, A. (2019), Inisiasi mental health awareness melalui screening dan promosi kesehatan mental pada mahasiswa Universitas Sriwijaya.

Matthews, G. (2000). Distress. Fink (ed) in Encyclopedia of stress Volume 1 (A-D): New York: Academic press.

Mirowsky, J., \& Ross, C. E. (2003). Social causes of psychological distress. New York: Aldine De Gruyer.

NAMI. (2012). College students speak. A survey on mental health. NAMl, 8- 10. Retrieved from http://www.nami.org/collegesurvey.

O'Connor, M., Casey, L., \& Clough, B. (2014). Measuring mental health literacy - a review of scale-based measures. Journal of Mental Health, 23(4), 197-204. Doi: 10.3109/09638237.2014.910646.

O'Connor, M. \& Casey, L. (2015). The mental health literacy scale (MHLS): A new scale-based measure of mental health literacy. Psychiatry Research, 229(1), 511-516. Doi: http"//dx.doi.org/10.1016/j.psychres.2015.05.0 64.

Pederelli, P., Yeung, Nyer \& Zulauf (2016). College Students: Mental Health Problems and Treatment Considerations. Academic Psychiatry. 39 (5).

Pengpid, S. \& Peltzer, K. (2020). Prevalence and associated factors of psychological distress among a national sample of in-school adolescents in Morocco. BMC Psychiatry, 20(475), 1-11. Doi: https://doi.org/10. 1 186/s1 2888-020-02888-3.
Reis, F.J., Lopes, D., Rodrigues, J.S., Gosling, A.P., \& Gomes, M.T. (2014). Psychological distress and quality of life in leprosy patients with neuropathic pain. Leprosy Review. 85, 186193

Ryff, C.D. (1989). Happiness is everything, or is it? Explorations on the meaning of psychological well-being. Journal of personality and social psychology. 57(6), 1069-1081.

Ryff, C. D., \& Keyes, C. L. M. (1995). The structure of psychological well-being revisited. Journal of personality and social psychology, 69(4).

Tian, S., Zhang, T-Y., Miao, Y-M., \& Pan, C-W. (2021). Psychological distress and parental involvement among adolescents in 67 lowincome and middle-income countries: A population-based study. Journal of Affective Disorders, 282, 1101-1109. Doi: https://doi.org/10.1016/j.jad.2021.01.010.

Vasquez, A.E (2016). Mental Health Literacy among College Students: Conceptualizations of Mental and Emotional Health. Pacific University Common Knowledge. https://commons.pacificu.edu/cgi/viewconten t. cgi? article $=1042 \&$ context $=$ cassoc

Wei, Y., McGrath, P.J., Hayden, J., \& Kutcher, S. (2016). Measurement properties of tools measuring mental health knowledge: a systematic review. BMC Psychiatry, 16(297), 116. Doi: 10.1 186/s1 2888-016-1012-5.

Womens Brain Health Initiative (2015). The reason why mental health disorders emerge in your early 20s. Canadian and U.S. charitable foundation established in 2012 and is solely dedicated to protecting the brain health of women. https://womensbrainhealth.org/thinktank/think-ahead/the-reason-why-mentalhealth-disorders-emerge-in-your-early-20s

World Health Organization. (2005). Promoting mental health; concept, emerging evidence and practice; report of the World Health Organization. Department of Mental Health and Substance Abuse in collaboration with the Victorian Health Promotion Foundation and the University of Melbourne.

World Health Organization (2013). Mental Health Action Plan 2013-2020. http://www.who.int/mental_health/publications/ action_plan/en/ 